\title{
Konaklama İşletmelerinde Algılanan Örgütsel Destek ve Yenilikçi İş Davranışı Arasındaki İlişki
}

DOI: $10.26466 /$ opus.578547

\author{
Sibel Sü Eröz ${ }^{*}$-Seher Şıttak** \\ ${ }^{*}$ Dr. Öğr. Üyesi, KırklareliÜniversitesi, TurizmFakültesi, Kırklareli / Türkiye \\ E-Posta: sibeleroz@hotmail.com \\ ORCID: 0000-0001-5735-9071 \\ **Y.L.Öğr., KırklareliÜniversitesi, SBE, TurizmİşletmeciliğiBölümü, Kırklareli / Türkiye \\ E-Posta: $\underline{\text { s.sittak15@gmail.com }}$ \\ ORCID: $\underline{0000-0002-4290-437 X}$
}

Öz

Araştırmanın temel amacı konaklama işletmelerinde çalışanların algıladıkları örgütsel destek ile yenilikçi iş davranışları arasındaki ilişkiyi belirlemektir. Çalışmada, örgütsel destek konusunda yüksek algıya sahip çalışanların örgütlerine daha fazla katkıda bulunmak, için daha fazla çalışacağı ve bunun için de yenilikçi iş davranışlarını arttıracağı öngörülmektedir. Araştırma evrenini Türkiye'de Çanakkale il merkezinde faaliyet gösteren 3, 4 ve 5 yıldızlı konaklama işletmesi çalışanları oluşturmaktadır. Araştırmada gerekli verileri toplamak amacıyla, "Kişisel Bilgi Formu", Eisenberger ve arkadaşlar (1997) tarafindan geliştirilen "Algılanan Örgütsel Destek Ölçeği" ve De Jong ve Den Hartog (2010) tarafından geliştirilen "Yenilikçi Davranış Ölçeği" kullanılmıştır. Çalışmanın verileri IBM SPSS Statistic 20.0 istatistik paket programı ile analiz edilmiştir. Yapılan analizler sonucunda algılanan örgütsel destek ve yenilikçi iş davranışı arasında pozitif yönde, orta düzeyde ve anlamlı bir ilişki oldu$\breve{g} u$ belirlenmiştir. Ayrıca algllanan örgütsel destek ve yenilikçi iş davranışı ile cinsiyet ve eğitim düzeyi değişkenleri arasında anlamlı bir farklılık bulunamamıştır. Buna karşın algilanan örgütsel destek ve yenilikçi iş davranışı ile medeni durum, yaş, işletmedeki pozisyon, sektördeki çalışma süresi, işletmedeki çalışma süresi ve çalışılan işletmenin yıldız sayısı değişkenleri arasında anlamlı bir farklılık bulunmuştur.

AnahtarKelimeler: Alg̨lanan Örgütsel Destek, Konaklama İşletmeleri, Yenilikçi İş Davranışı 


\title{
The Relationship Between The Perceived Organizational Support and Innovative Business Behavior in The Hospitality Management
}

\begin{abstract}
The main purpose of this research is to determine the relationship between the perceived organizational support and innovative business behavior in the hospitality managements. Population of the research has included hospitality management employees in 3, 4 and 5 stars hotels in the city centrum of Çanakkale Province in Turkey. A questionnaire as a data collection tool used in this research included demographic information of the participants, "Perceived Organizational Support Scale" developed by Eisenberger et al. (1997) and "Innovative Work Behavior Scale" developed by De Jong ve Den Hartog (2010). The data has been analyzed by using the statistical packet programme IBM SPSS Statistic 20.0. The results of the analysis show that there is a positive, medium level and significiant correlation between perceived organizational support and innovative business behavior. Furthermore, no significant differences were found among the perceived organizational support, innovative business behavior and the gender and level of education variables. On the other hand, the significant differences were found among the perceived organizational support, innovative business behavior and marital status, age, position in management, working time in the sector, working time in the management and number of management's star variables.
\end{abstract}

Keywords: Perceived Organizational Support, Innovative Work Behavior, Hospitality 


\section{Giriş}

Modern dünyada çalışma yaşamı kalitesinin göstergesi olarak görülen birçok değişkenin varlığ çalışanların gerek işe girmesinde gerekse de o işyerinde kalıp etkin ve verimli bir biçimde çalışmasında belirleyici olmaktadır. Bu nedenle de işletmeler çalışanların etkin ve verimli bir biçimde çalışması için gerekli koşulları sağlamaya çalışmaktadırlar. Devletler tarafından çalışan hakları yasalar ile iyileştirilmeye çalışılırken, işletmeler tarafından çalışanlar daha çok psikolojik yönleri ile ele alınmakta ve verimliliklerini bu yol ile artırma yolları araştırılmaktadır.

Turizm sektöründe var olan küresel rekabetin şiddetini giderek arttırmakta olduğu ve bundan en çok konaklama işletmelerinin etkilendiği ifade edilebilir. Konaklama işletmelerinde rekabet üstünlüğü çalışanların nitelikleri ile sağlanmakta ve girişimci, yaratıcı, yeniliklere açı çalışanların varlığı işletme içerisinde hizmet kalitesini dolayısıyla müşteri memnuniyetini arttırmaktadır. Güçlü Nergiz (2016)'in belirttiği üzere bu durum turizm işletmelerinde de beşeri kaynakların değerini maddi kaynakların çok daha ötesine taşımaktadır. İşletmelerce çalışanlara verilen önem ve destek bu noktada önem kazanmaktadır. Fakat bir o kadar önemli olan çalışanların bu desteği nasıl algıladığı ile ilgilidir. Ayrıca konaklama işletmelerinde rekabetle baş edebilmenin ön koşulu yenilik olarak görülmektedir. Gerek yeniliğin ortaya çıarılması, gerekse de benimsenmesi ve uygulanmasının çalışanlarının yenilikçi iş davranışı ile ilişkili olduğu ifade edilebilir.

Yeniliğe güçlü biçimde destek veren bir işletmenin çalışanları, yenilikçi davranışlarını performans kazanımlarını elde etmede daha yararlı olarak algılamaktadırlar (Yuan ve Woodman, 2010). Örgütü geliştirmeye yönelik anonim, gönüllü önerilerin yapıcılığı, çalışanların örgütün katk1larına değer verdiğini ve refahlarını önemsediğini algılaması ile daha fazla artmaktadır. Bu tür yenilikçi öneriler işletmelerin büyümesi ve başarısı için önemlidir (Katz, 1964; Smith vd., 1983 akt: Eisenberger, Fasolo ve Davis-LaMastro, 1990).

Ayrıca verimlilik odaklı bir açıdan bakıldığında, yenilik için uygun bir örgüt ikliminin varlığı değişime duyulan ihtiyacı ve yeniliğin örgütü daha verimli ve başarılı hale getireceğine olan inancı da göstermektedir (Yuan ve Woodman, 2010). İşletme kültürüne yerleşmiş olan bu değer ve 
inançlar zaman içerisinde örgütün sosyalleşme süreçleri aracılığıyla çalışanlar tarafından birbirlerine aktarılacak ve içselleştirilecektir (Chatman, 1991; Harrison ve Carroll, 1991 akt: Yuan ve Woodman, 2010). Bu nedenle, yeniliğe güçlü destek veren işletmelerde çalışanların yeniliğin değerli olduğu ve performans kazancı getireceği inancını paylaşması önemlidir (Yuan ve Woodman, 2010).

Eisenberger ve arkadaşları (1990), yenilik ve kendiliğinden problem çözmenin algılanan destekle de ilişkilendirilebileceğini belirtmektedirler. Benzer bir biçimde Yıldız, Uzun ve Coşkun (2017) da sosyal değişim teorisi ve örgütsel destek teorisini temel alarak çalışanların psikolojik olarak güçlendirilmesinin ve desteklenmesinin işyerindeki yenilikçi davranışlarını arttıracağını öngörmektedirler. Dolayısıyla bu çalışmada da çalışanların örgütsel desteği olumlu olarak algıladıklarında yeniliğe daha çok odaklanacakları düşünülmektedir.

$\mathrm{Bu}$ amaçla çalışmada konaklama işletmelerinde çalışanların algıladıkları örgütsel destek ile yenilikçi iş davranışı arasındaki ilişki araştırılmaktadır. Öncelikli olarak konu ile ilgili kavramlar tanımlanmış ve literatürde algılanan örgütsel destek ve yenilikçi iş davranışları arasında ilişki kuran çalışmalar belirlenmeye çalışılmıştır. Çalışmanın metodoloji kısmında ise çalışmada kullanılan araştırma yöntemleri, yapılan analizler ve elde edilen sonuçlar yer almaktadır. Tartışma ve sonuç bölümünde ise çalışmada elde edilen bulgular literatürdeki araştırmaların sonuçları ile karşılaştırılmaktadır. Ayrıca konaklama işletmelerinin yöneticilerine konuyla ilgili öneriler sunulmaktadır.

\section{Teorik Çerçeve}

\section{Algılanan Örgütsel Destek}

Algılanan örgütsel destek (AÖD) Eisenberger, Huntington, Hutchison ve Sowa (1986) tarafından, "çalışanların örgüt için yaptıkları katkılarına değer verildiğine ve örgütün refahları ile ilgilenmelerine dair algıları" olarak tanımlanmaktadır. Hellman, Fuqua ve Worley (2006) bu tanımı temel alarak AÖD'i, “çalışanların bir emek sonucu işyerine yapmış olduğu katkının, örgüt tarafından bir değer olarak algılanması, üretkenliğinin ve örgüte sadakatinin sonucunda ödül vb. unsurlarla motive edilerek 
kendisinin iyiliğinin düşünüldüğünü algılaması" olarak tanımlamaktadırlar. Stamper ve Johlke (2003), örgütsel destek algısının, işverenler ve çalışanlar arasındaki çoklu etkileşimlerle zaman içerisinde geliştiği düşüncesinden hareket ederek "işverenler ve çalışanların iş örgütlerinin kendilerine ne derece bağlı olduğunu algıladıklarını yansıtmasıdır" şeklinde bir tanımlama geliştirmişlerdir. AÖD kavramının temelinde Levinson'ın "Kişileştirme Teorisi" ve Blau'nun "Sosyal Değişim Teorisi" bulunduğu ifade edilebilir.

Levinson'ın "Kişileştirme Teorisi"nde işverenin kişileştirilmesi; örgüt temsilcilerinin hukuki, ahlaki ve finansal sorumluluk ile hareketi; sürekliliği sağlayan ve rol davranışlarını belirleyen örgüt politikaları, normlar ve kültür üzerindeki etkileri ve örgütün bireysel çalışanlar üzerindeki gücünün örgüt tarafından sağlanıyor olması ile açıklanmaktadır. Böylelikle çalışanlar, örgüt temsilcileri tarafından gerçekleştirilen birçok eylemi örgütün kendisinin temsili olarak görmektedirler (Eisenberger, Cummings, Armeli ve Lynch 1997). Çalışanlar işletmenin kişileştirilmelerine dayanarak, işletmeden gördükleri olumlu ya da olumsuz davranışları, işletmenin bir göstergesi olarak görmektedirler (Aselage ve Eisenberger, 2003).

Kişilerarası ilişkilerin başlatılmasını, güçlendirilmesini ve sürdürülmesini açıklamak için geliştirilen "Sosyal Değişim Teorisi" ise, bireyler ve iş organizasyonları arasındaki ilişkileri anlamak için kavramsal bir temel sağlamaktadır. Sosyal değişim teorisinin merkezi, insanların başkalarından aldıkları olumlu yaklaşıma, olumlu yanıt vermelerini zorunlu kılan karşlıklılık normudur (Blau, 1964; Gouldner, 1960 akt: Eisenberger vd., 1997). Diğer bir ifadeyle bireylerin algisı olumlu olduğunda davranışları da olumlu olmaktadır. Eğer algıları olumsuz ise olumsuz tutum ve davranışlar sergilemektedirler (Yıldız, Uzun ve Coşkun 2017). Hem çalışan hem de işveren karşılıklılık normunu ilişkilerine uyguladığı ölçüde, bu her iki taraf için de olumlu sonuçlara yol açacaktır (Rhoades ve Eisenberger, 2002). Cropanzano ve Mitchell (2005), sosyal değişim ilişkilerinin, işverenlerin çalışanlarla ilgilendiğinde geliştiğini ve bunun da işletmeler için yararlı sonuçlar ortaya çıkardığını belirtmektedirler. Karş11ıklılık normu temeline göre, çalışanlar tarafından AÖD kuruluşa olan duygusal bağlılığı güçlendirecek ve örgüt adına yapılan çalışmaları artıracaktır (Eisenberger vd., 1997). 
AÖD, çalışanların örgütün hedeflerini ve hedeflerini gerçekleştirmesine yardımcı olmak zorunda olduğunu düşündüğü ve örgütün lehine artan çabalarının daha büyük ödüller kazanmasına neden olacağı bir sosyal değişim süreci başlatmaktadır. AÖD ayrıca sosyal ve duygusal ihtiyaçları karşılamakta ve örgütle daha fazla özdeşleşme ve örgüte daha fazla bağlılık, organizasyonun başarılı olmasına yardım etme arzusunun artması ve daha fazla psikolojik iyi oluş ile sonuçlanmaktadır (Kurtessis, vd., 2015).

Kurtessis ve arkadaşları (2015) AÖD sonuçlarını; örgüte ve işe pozitif yönelim, öznel iyi oluş ve davranışsal çıtılar olmak üzere üç kategoride toplamaktadırlar. Çalışanlar, örgüt tarafından tercih edilen faaliyetlerden kaynaklanacak olası maddi ve sembolik faydaları değerlendirmek için algilanan örgütsel desteği kullanabilirler. AÖD ve emek-ödül beklentileri arasındaki ilişki çift yönlü olabilir. Yüksek çaba için beklenen ödül güçlenebilir ve dolayısı ile çalışanların kuruluşun katkılarına değer verdiğine dair algısından etkilenebilir (Eisenberger, vd., 1990).

Yüksek AÖD (a) onay, saygınlık ve sosyal kimlik ihtiyaçlarını karşılayıp (b) örgüt için yapılmış üstün geleneksel performans ve ekstra rol davranışının tanınması ve ödüllendirilmesi beklentisini oluşturmaktadır (Eisenberger, vd., 1997).

Çalışanlar örgüt içerisinde sergiledikleri performansın karşılığı almak için beklenti içinde olacaklardır. Bu çaba-sonuç beklentisi, çalışanın organizasyonel hedefleri karşılamak için daha fazla çaba harcayacağına ve böylece algılanan desteğin övgü ve onaylama gereksinimlerini karşıladığ1 ölçüde çalışan örgütsel üyeliğini öz-kimliğine dahil edecek ve organizasyonun hedeflerine ulaşmasında daha büyük katılım ve performans sergileyecektir (Eisenberger vd., 1986). Aynı zamanda kuruluşun kendi adına yapılan çabaları fark etme ve ödüllendirmeye ilişkin değişim yükümlülüklerini yerine getirmeye özen göstermesi çalışanlarda güven duygusu oluşturmaktadır (Eisenberger vd., 1990). 


\section{Yenilikçi İş Davranışı}

Kuruluşların değer yaratmasında merkezi bir rol oynayan ve aynı zamanda sürdürülebilir rekabet avantajlarının önemli bir kaynağı olarak kabul edilen yenilik kavramının iktisadi açıdan tanımının Schumpeter tarafından 1920'lerin sonlarında yapıldığı kabul edilmektedir. Schumpeter'e göre yenilik (Crossan ve Apaydin, 2010) "bir şeyleri farklı yapma olarak özetlenebilen yeni bir ürün ya da ürüne yeni bir nitelik ekleme; yeni bir üretim yöntemi; yeni bir pazar; yeni bir tedarik kaynağı, yeni bir örgüt yapısı olarak yansıyan üretim çıktıları olarak" tanımlanmaktadır. Kısacası ekonomik hayatın akışında bir şeyleri farklı yapma yenilik terimiyle karşılanmaktadır (Dolanay, 2009). Yeniliğin temeli, bireylerin yeni bir fikre sahip olması ve bu fikri başlangıçtaki durumunun ötesinde geliştirmesidir. Yeniliğin işletmeler açısından önemi ve özünde insanın olması işyerlerinde yenilikçi iş davranışının (YID) tanımlanmasını da beraberinde getirmiştir.

Yuan ve Woodman (2010) işyerinde yenilikçi davranışı "bir çalışanın, iş rolü, iş birimi veya örgütü için yeni fikirler, ürünler, süreçler ve prosedürleri bilinçli olarak başlatması ya da uygulaması" olarak tanımlamaktadırlar. Li ve Zheng'e göre (2014) YİD, "çalışanların yenilikçi düşünce biçimlerini kullanmalarını, müşteri taleplerindeki değişimlere hızlı ve doğru bir şekilde cevap verebilmelerini sağlayan, kişisel ve organizasyonel verimlilik amaciyla organizasyonda yenilikçi düşüncenin oluşturulması, tanıtılması ve uygulanmasıdır". De Jong ve Den Hartog (2008)'a göre YID, "yeni ve faydalı fikirlerin, süreçlerin, ürünlerin ya da prosedürlerin bilinçli bir biçimde ortaya çıkarılması ve uygulanmasını (bir iş rolü, grup veya organizasyon içinde) başarmayı amaçlayan bireysel davranışlar" olarak tanımlanmaktadır.

De Jong ve Den Hartog (2008) YİD’nı ölçmek üzere geliştirdikleri ölçekte yeniliği fırsatların keşfedilmesi, fikir üretme, fikre destek bulma ve uygulama olmak üzere dört boyut olarak ele almaktadırlar. Janssen de (2010) YİD'nın; fikir üretme, fikir geliştirme ve fikir gerçekleştirme olmak üzere üç farklı davranışsal görevden oluştuğunu belirtmektedir. 


\section{Algılanan Örgütsel Destek (AÖD) ve Yenilikçi İş Davranışı (YİD) Ara- sındaki İlişki}

Yapılan literatür çalışmasında Çapraz ve diğ. (2014) İzmir'de bulunan tarım, lojistik, turizm, ileri teknoloji ve yenilenebilir enerji sektörlerinde yer alan 56 firmada çalışan toplam 208 kişilik bir örneklem üzerinde çalışanlar perspektifinden inovatif iş davranışının belirleyicilerini incelerken AÖD'i de incelemişlerdir. Yapılan frekans analizi sonucunda AÖD'in YİD’larını etkilediği görüşüne katılımcıların \% 33'ü katılıyorum, \%56 ne katılıyorum ne katılmıyorum, \%7'si katılmıyorum cevabını verdikleri görülmektedir. \%56 oranındaki kararsız çalışanların varlığını çalışanların bireysel özelliklerinin YİD ortaya koymada örgütsel öğelerin önüne geçtiğinin bir göstergesi olarak yorumlamaktadırlar (Çapraz ve diğ, 2014). Ayrıca yapılan Pearson korelasyon analizi sonucunda; inovasyona yönelik destek ile inovatif davranışı tanıma, farketme, inovatif davranışı ödüllendirme ve kaynak yaratma arasında pozitif yönlü ve anlamlı bir ilişki bulunmuştur.

Yıldız, vd. (2017) İstanbul'da beyaz eşya sektöründe çalışan toplam 436 kişiden oluşan örneklem üzerinde yaptıkları çalışmalarında çalışanların AÖD ve YIDD arasında pozitif yönde anlamlı bir ilişki olduğu ve AÖD'in YİD'nın istatistiki olarak anlamlı ve pozitif yönde belirleyicisi olduğu sonucuna ulaşmışlardır. Ayrıca çalışmada AÖD'in yenilikçi davranışları pozitif yönde etkilediği belirlenmiştir.

Qi, Liu ve Hu (2019) Çin'de toplam 6 şehirde banka, hukuk kurumları, tedarik mağazaları gibi 15 hizmet temelli işyerlerinde yapmış oldukları çalışmalarında AÖD ile çalışanların YİD arasında pozitif yönde bir ilişki olduğunu ortaya koymuşlardır. Ayrıca çalışmada AÖD'in yenilikçi davranışları pozitif yönde etkilediği belirlenmiştir.

Özer (2014) Türk Telekom Kurumsal Müşteri Başkanlığı'na bağlı çalışan toplam 241 kişiden oluşan örneklem üzerinde yaptıkları çalışmalarında AÖD ile takım inovasyonu ile arasında istatistiksel açıdan anlamlı bir ilişki bulmuşlardır.

Buna karşın Yuan ve Woodman (2010) Amerika'da bulunan bilgi teknolojisi hizmeti, bilgisayar sistemi geliştirme, mobilya tasarımı/üretimi, kimyasal cihazlar geliştirme/imalat işletmelerinde çalışan 425 çalışan ve 
95 yönetici toplam 520 kişilik örneklem üzerinde yaptıkları çalışmalarında çalışanların AÖD ile YİD arasında bir ilişki olmadığı sonucuna ulaşmışlardır. Bu durumu yenilik yapmanın çalışanlar tarafından beklenen pozitif performans kazancı getireceğine inanmamalarından kaynaklandığını oluşturdukları model ile göstermektedirler.

\section{Metodoloji}

\section{Araştırma Soruları}

Araştırma çerçevesinde aşağıdaki sorulara yanıt aranmaktadır.

1. Konaklama işletmesi çalışanlarının AÖD ile YİD algıları arasında bir ilişki var mıdır?

2. Konaklama işletmesi çalışanlarının AÖD algıları ile araştırmada yer alan kategorik sorulara (cinsiyet, medeni durum, yaş, eğitim düzeyi, işletmedeki pozisyon, sektördeki çalışma süresi, işletmedeki çalışma süresi, çalışılan işletmenin yıldız sayısı) göre farklılaşmakta mıdır?

3. Konaklama işletmesi çalışanlarının YİD algılamaları araştırmada yer alan kategorik sorulara (cinsiyet, medeni durum, yaş, eğitim düzeyi, işletmedeki pozisyon, sektördeki çalışma süresi, işletmedeki çalışma süresi, çalışılan işletmenin yıldız sayısı) göre farkl1laşmakta mıdır?

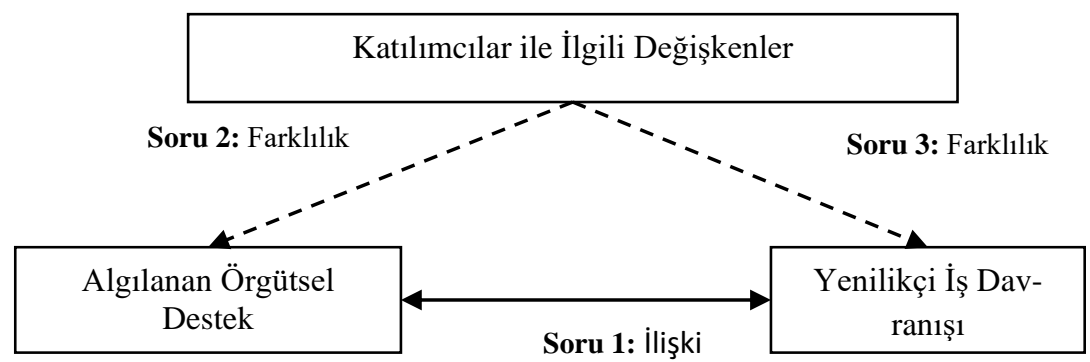

Şekil 1. Araştırmanın Modeli 


\section{Araştırmanın Evren ve Örneklemi}

Araştırma evrenini Türkiye'de Çanakkale il merkezinde faaliyet gösteren 3, 4 ve 5 yıldızlı konaklama işletmesi çalışanları oluşturmaktadır. Çanakkale il merkezinde 12 adet 3 yıldızlı, 5 adet 4 yıldızlı ve 2 adet 5 yıldızlı konaklama işletmesi bulunmaktadır. Çalışmada 397 çalışana ulaşılmıştır.

\section{Araştırmanın Yöntemi}

$\mathrm{Bu}$ araştırma genel tarama modelinde bir çalışmadır. Genel tarama modelleri; çok sayıda elemandan oluşan bir evrende, evren hakkında genel bir yargıya varmak amacı ile evrenin tümü ya da ondan alınacak bir grup, örnek ya da örneklem üzerinde yapılan tarama düzenlemeleridir (Karasar, 2009). Ayrıca verilerin toplanmasında yüz yüze anket tekniği kullanılmıştır. Anketler uygulanmadan önce çalışanlara çalışmanın amaCı açıklanmıştır. Elde edilen veriler IBM SPSS Statistic 20.0 istatistik paket programından yararlanılarak analiz edilmiştir.

\section{Veri Toplama Aracı}

Araştırmada gerekli verileri toplamak amacıyla, "Kişisel Bilgi Formu", "AÖD Ölçeği" ve "Yenilikçi Davranış Ölçeği" kullanılmıştır.

"Kişisel Bilgi Formu" cinsiyet, medeni durum, yaş, eğitim düzeyi, işletmedeki pozisyon, sektördeki çalışma süresi, işletmedeki çalışma süresi ve çalışılan işletmenin yıldız sayısı değişkenlerini içeren 8 adet kategorik sorudan oluşmaktadır.

"AÖD Ölçeği", Eisenberger ve arkadaşları (1986) tarafından 36 madde olarak geliştirilmiş ve yine Eisenberger ve arkadaşları (1997) tarafından 8 ifade olarak kısaltılmıştır. Tek boyutlu bu ölçeğin güvenilirliği 0.90 olarak tespit edilmiştir (Eisenberger vd., 1997). "Çalıştığım kurumda, kuruma yönelik katkılarıma değer verilir" olarak ifade edilen 6. madde ve "Çalıştı̆̆ım kurum, bana çok az yakınlık gösterir" olarak ifade edilen 7. madde ters kodlanmaktadır. Ölçek, "kesinlikle katılmıyorum" ile "kesinlikle katılıyorum" arasında değişen 5'li Likert tipi bir ölçektir. 
"Yenilikçi Davranış Ölçeği" 2010 yılında De Jong ve Den Hartog (2010) tarafından geliştirilmiş ve Çimen ve Yücel (2017) tarafından Türk kültürüne uyarlanmıştır. Ölçeğin özgün formunda on madde ve dört boyut bulunmaktadır. Bu dört boyut Çimen ve Yücel (2017: 371) tarafından "fikir üretme (m1 ve m2)", "araştırma (m3, m4 ve m5)", "destekleme (m6 ve $\mathrm{m} 7)$ " ve "uygulama ( $\mathrm{m} 8, \mathrm{~m} 9$ ve $\mathrm{m} 10)$ " olarak belirtilmiştir. Ölçek, "hiçbir zaman" ile "her zaman" arasında değişen 5'li Likert tipi bir ölçektir (Çimen ve Yücel 2017).

\section{Bulgular}

\section{Güvenilirlik Analizi Sonucu}

Elde edilen verilerle yapılan güvenilirlik analizi sonucunda; “AÖD Ölçeği" Cronbach's Alpha değeri 0,755 (n=8), "Yenilikçi Davranış Ölçeği $\mathrm{i}^{\prime}$ Cronbach's Alpha değeri 0, $931(n=10)$ olarak bulunmuştur. Ölçekte yer alan ifadelerin tamamı için Cronbach's Alpha değeri 0,899 $(n=18)$ olarak bulunmuştur. Bulunan bu değer literatürde kabul edilebilir değer olan $\alpha=0,70$ 'in (Altunışık, Coşkun, Bayraktaroğlu ve Yıldırım, 2007) üzerinde olması ile güvenirliliğinin oldukça iyi olduğunu göstermektedir.

\section{Faktör Analizi Sonuçları}

Ankette yer alan ölçeklerin geçerliliğini test etmek üzere açıklayıcı faktör analizi yapılmıştır. Araştırmada "AÖD Ölçeği" ve "Yenilikçi Davranış Ölçeği" ifadelerine yönelik olarak faktör analizi için veri setinin faktör analizine uygun olup olmadığını değerlendirmek amacıyla KaiserMeyer-Olkin (KMO) değerine ve Bartlett testine bakılmıştır.

Araştırmada "AÖD Ölçeği" KMO katsayı değeri ,920 bulunmuştur, Barlett küresellik testi sonucu da [Approx. Chi-Square=2011,491, df=28, sig .000 ( $\mathrm{p}<.001)$ ] olarak bulunmuştur. KMO ve Bartlett testi sonuçlarına göre faktör analizi yapılmasına karar verilmiştir. Yapılan faktör analizi sonucunda tek faktörlü bir yapı elde edilmiştir. Bu tek faktörlü yapının açıkladığı toplam varyans \% 62.095'dir.

Araştırmada "Yenilikçi Davranış Ölçeği" KMO katsayı değeri ,930 bulunmuştur, Barlett küresellik testi sonucu da [Approx. Chi- 
Square $=2829,056, \mathrm{df}=45$, sig $.000(\mathrm{p}<.001)]$ olarak bulunmuştur. KMO ve Bartlett testi sonuçlarına göre faktör analizi yapılmasına karar verilmiştir. Yapılan faktör analizi sonucunda özgün ölçeğin aksine tek faktörlü bir yapı elde edilmiştir. Bu tek faktörlü yapının açıkladığı toplam varyans \% 63.181'dir.

\section{Analize Uygunluk Testleri}

Shapiro-Wilks ve Kolmogorov-Smirnov (K-S) testleri, puanların normalliğe uygunluğunu analiz etmede kullanılan testlerdir (Çokluk, Şekercioğlu ve Büyüköztürk, 2016). Araştırma sonucu elde edilen veriler Kolmogorov-Smirnov ve Shapiro-Wilks ile normallik sinamasina tabi tutulmuştur. Yapılan analiz sonucunda her iki testin de sig. değerleri 0,000 olarak bulunmuştur. Verilerin sig. değeri $0,05^{\prime}$ ten küçük olduğu için verilerin normal dağılım sergilemediği ifade edilebilir. Elde edilen bu sonuçtan dolayı araştırmada parametrik olmayan testler kullanılmıştır. Elde edilen bulgular \% 95 güven aralığında, \%5 anlamlılık düzeyinde değerlendirilmiştir.

\section{AÖD ile YỉD Arasındaki İlişki Analizi}

Tablo 1'de AÖD ölçeğinden alınan puanlarla YİD puanları arasındaki ilişkiyi belirlemek üzere yapılan Spearman Sıra Farkları Korelasyon analizi sonucu gösterilmektedir. Elde edilen sonuçlarda puanlar arasında istatistiksel açıdan pozitif yönde, orta düzeyde ve anlamlı bir ilişki olduğu görülmektedir $(0,000<0.05, r=, 490, \mathrm{~N}=397)$. Çokluk, vd. (2016), korelasyon katsayısının değerinin 0.30-0.69 arasında olması durumunda orta düzeyde bir ilişki olarak yorumlanması gerektiğini belirtmektedirler.

Tablo 1. AÖD ile YİD Arasındaki İlişkiyi Belirlemek Üzere Yapılan Spearman Sıra Farkları Korelasyon Analizi Sonucu

\begin{tabular}{llll}
\hline Değişken & n & r & p \\
\hline $\begin{array}{l}\text { AÖD } \\
\text { YìD }\end{array}$ & 397 &, 490 & 0,000 \\
\hline
\end{tabular}




\section{Katılımcıların Özellikleri ile AÖD'e İlişkin Farklılık Testleri}

İkili gruplar arası farklılığın belirlenebilmesi için analizde Mann Whitney $\mathrm{U}$ testi kullanılmıştır. Tablo 2'ye göre katılımcıların cinsiyetlerine ile AÖD puan ortalamaları arasındaki farklılık istatistiksel olarak anlamlı değildir ( $\mathrm{p}, 046>0.05)$. Katılımcıların AÖD puan ortalamaları medeni durum değişkenine göre anlamlı bir farklılık göstermektedir $(\mathrm{p} .000<0.05)$. Evli katılımcıların AÖD puan ortalamaları $(\overline{\mathrm{X}}=219,82)$ bekar katılımcların AÖD puan ortalamalarından $(\bar{X}=173,12)$ daha yüksektir.

Tablo 2.Katılımcılar Tarafından AÖD Puanlarının Cinsiyet ve Medeni Duruma Göre Farklılı̆̆ını Gösteren Mann Whitney U Testi Sonuçları

\begin{tabular}{llllllll}
\hline \multirow{2}{*}{ Değişkenler } & Gruplar & $\mathbf{N}$ & $\begin{array}{l}\text { Sıra Orta- } \\
\text { laması }\end{array}$ & $\begin{array}{l}\text { Sira } \\
\text { Toplamı }\end{array}$ & $\begin{array}{l}\text { Man } \\
\text { Whitney U }\end{array}$ & Z & p \\
\hline \multirow{2}{*}{ Cinsiyet } & Kadın & 168 & 208,82 & 47820,50 & 16989,500 & $-1,999$ &, 046 \\
& Erkek & 229 & 185,61 & 31182,50 & & & \\
Medeni & Evli & 220 & 219,82 & 48361,00 & 14889,000 & $-4,046$ &, 000 \\
Durum & Bekar & 177 & 173,12 & 30642,00 & & & \\
\hline
\end{tabular}

${ }^{*} p<0.05$

İkiden daha fazla grup arasındaki farkın belirlenebilmesi için analizde Kruskall Wallis Testi testi kullanılmıştır. Ayrıca farklılıkların kaynağını belirleyebilmek her bir grup, ikili gruplar halinde alınarak, MannWhitney $\mathrm{U}$ testine tabi tutulmuşlardır.

Tablo 3'e göre katılımcların eğitim düzeyine göre YİD puan ortalamaları arasındaki farklılık istatistiksel olarak anlamlı değildir ( $\left.\mathrm{p}_{0,62}>0.05\right)$.

Katılımcıların yaş düzeyine göre AÖD puan ortalamaları istatiksel olarak anlamlıdır $(\mathrm{p}, 000<0.05)$. Yapılan Mann-Whitney U testi sonucuna göre; 18-22 yaş arasındaki katılımcıların en düşük AÖD puan ortalamasina sahip olduğu görülmektedir $(\bar{X}=100,27)$. Yaş grubu 23-27 yaş arasındaki katılımcılar $(\bar{X}=152,83), 33-37$ yaş $(\bar{X}=230,88), 38-42$ yaş $(\bar{X}=212,25)$, $43-47$ yaş $(\bar{X}=261,66)$ ve 48 yaş üstü $(\bar{X}=236,05)$ gruplarına göre; yaş grubu 28-32 yaş arasındaki katılımcılar $(\bar{X}=164,08)$, 33-37 yaş $(\bar{X}=230,88)$ ve 43-47 yaş $(\bar{X}=261,66)$ gruplarına göre; yaş grubu $38-42$ yaş $(\bar{X}=212,25)$ arasındaki katılımcılar, 43- 47 yaş $(\bar{X}=261,66)$ grubuna göre daha düşük 
AÖD puan ortalamasına sahiptirler. Genel bir ifade ile yaş arttıkça AÖD puan ortalamalarının da arttığı söylenebilir.

Katılımcıların işletmedeki pozisyonuna göre AÖD puanları istatiksel olarak anlamlıdır $(\mathrm{p}, 000<0.05)$. Yapılan Mann-Whitney $U$ testi sonucuna göre; işletme müdürleri ( $\bar{X}=336,06)$, departman müdürleri $(\bar{X}=324,23)$ ve şeflerin $(\bar{X}=251,90)$ AÖD puan ortalamaları, çalışanların ( $\bar{X}=175,73)$ AÖD puan ortalamalarından daha yüksektir. Elde edilen verilere göre işletmede en az AÖD çalışanlar tarafından hissedilmektedir.

Katılımcıların sektördeki çalışma süresine göre AÖD puanları istatiksel olarak anlamlıdır ( $\mathrm{p}, 000<0.05)$. Yapılan Mann-Whitney U testi sonucuna göre; sektördeki çalışma süresi 5 yıldan az olan katılımcıların AÖD puan ortalamaları $(\bar{X}=144,81)$ sektördeki çalışma süresi $5-10$ yıl $(\bar{X}$ $=194,90) 11-15$ yil $(\bar{X}=231,06)$ ve 16 yıl ve üzeri $(\bar{X}=266,86)$ olan katılımc1ların AÖD puan ortalamalarından daha düşüktür. Elde edilen verilere göre işletmede en az AÖD sektördeki çalışma süresi 5 yıldan daha az olan katılımcılar tarafından hissedilmektedir. Ayrıca sektördeki çalışma süresi 5-10 yıl arasında olan katılımcıların AÖD puan ortalamaları ( $\overline{\mathrm{X}}$ $=194,90)$ sektördeki çalışma süresi 16 yıl ve üzeri olan $(\bar{X}=266,86)$ katılımcllardan daha düşüktür.

Katılımcıların işletmedeki çalışma süresine göre AÖD puanları istatiksel olarak anlamlıdır ( $\mathrm{p}, 000<0.05)$. Yapılan Mann-Whitney U testi sonucuna göre; işletmedeki çalışma süresi 1 yıldan az olan katılımcıların AÖD puan ortalamaları $(\bar{X}=138,67)$ işletmedeki çalışma süresi 1-5 yıl $(\bar{X}$ $=208,87) 6-10$ yıl $(\bar{X}=259,19)$ ve 11 yıl ve üzeri $(\bar{X}=310,83)$ olan katılımcların puan ortalamalarından daha düşüktür. Elde edilen verilere göre işletmede en az AÖD işletmedeki çalışma süresi 1 yıldan az olan katılımc1lar tarafından hissedilmektedir. Ayrıca işletmedeki çalışma süresi 1-5 yıl arasında olan katılımcıların AÖD puan ortalamaları $(\bar{X}=208,87)$ sektördeki çalışma süresi 11 yıl ve üzeri $(\bar{X}=310,83)$ olan katılımcıların puan ortalamalarından daha düşüktür.

Katılımcıların çalışılan işletmenin yıldız sayısına göre AÖD puanları istatiksel olarak anlamlıdır $(\mathrm{p}, 006<0.05)$. Yapılan Mann-Whitney U testi sonucuna göre; 3 yıldızlı otel işletmelerinde çalışan katılımcıların AÖD puan ortalamaları $(\bar{X}=176,87), 4$ yıldızlı $(\bar{X}=213,51)$ ve 5 yıldızlı otel işletmelerinde çalışan katılımcılardan $(\bar{X}=215,21)$ daha düşüktür. Elde edilen 
verilere göre işletmede en az AÖD 3 yıldızlı otel işletmelerinde çalışan katılımcılar tarafından hissedilmektedir.

Tablo 3. Katılımcılar Tarafından AÖD Puanlarının Yaş, Eğitim Düzeyi, İşletmedeki Pozisyon, Sektördeki Çalışma Süresi, İşletmedeki Çalışma Süresi, Çalışılan İşletmenin Yıldız Sayısına Göre Farklılığını Gösteren Kruskall Wallis Testi Sonuçları

\begin{tabular}{|c|c|c|c|c|c|c|c|}
\hline Değişkenler & Gruplar & $\mathbf{N}$ & $\begin{array}{l}\text { Sira Orta- } \\
\text { lamas1 }\end{array}$ & $\begin{array}{l}\text { Chi- } \\
\text { Square }\end{array}$ & df & $p$ & Fark \\
\hline \multirow{7}{*}{ Yaş } & $18-22$ & 24 & 100,27 & 67,714 & 6 & ,000 & $1<2 \quad 2<6$ \\
\hline & $23-27$ & 78 & 152,83 & & & & $1<3 \quad 2<7$ \\
\hline & $28-32$ & 67 & 164,08 & & & & $1<4 \quad 3<4$ \\
\hline & $33-37$ & 55 & 230,88 & & & & $1<5 \quad 3<6$ \\
\hline & $38-42$ & 81 & 212,25 & & & & $1<6 \quad 5<6$ \\
\hline & $43-47$ & 81 & 261,66 & & & & $2<4$ \\
\hline & 48 ve üzeri & 11 & 236,05 & & & & $2<5$ \\
\hline \multirow{4}{*}{$\begin{array}{l}\text { Eğitim } \\
\text { Düzeyi }\end{array}$} & Orta Öğrenim & 39 & 203,31 & 7,319 & 3 & 0,62 & \\
\hline & Lise & 147 & 203,94 & & & & \\
\hline & Önlisans & 128 & 211,17 & & & & \\
\hline & Lisans & 83 & 169,46 & & & & \\
\hline \multirow{4}{*}{$\begin{array}{l}\text { İşletmedeki } \\
\text { Pozisyon }\end{array}$} & İşletme Müdürü & 8 & 336,06 & 54,680 & 3 & ,000 & $1<4$ \\
\hline & Departman Müdürü & 11 & 324,23 & & & & $2<4$ \\
\hline & Şef & 83 & 251,90 & & & & $3<4$ \\
\hline & Çalışan & 295 & 175,73 & & & & \\
\hline \multirow{4}{*}{$\begin{array}{l}\text { Sektördeki } \\
\text { Çalışma } \\
\text { Süresi }\end{array}$} & 5 yıldan az & 113 & 144,81 & 50,012 & 3 & ,000 & $1<2$ \\
\hline & $5-10$ yıl & 126 & 194,90 & & & & $1<3$ \\
\hline & $11-15 \mathrm{y} 1 \mathrm{l}$ & 114 & 231,06 & & & & $1<4$ \\
\hline & 16 yıl ve üzeri & 44 & 266,86 & & & & $2<4$ \\
\hline \multirow{4}{*}{$\begin{array}{l}\text { İşletmedeki } \\
\text { Çalışma } \\
\text { Süresi }\end{array}$} & 1 yıldan az & 119 & 138,67 & 61,401 & 3 & , 000 & $1<2$ \\
\hline & $1-5$ yil & 196 & 208,87 & & & & $1<3$ \\
\hline & $6-10 \mathrm{yll}$ & 76 & 259,19 & & & & $1<4$ \\
\hline & 11 yıl ve üzeri & 6 & 310,83 & & & & $2<3$ \\
\hline Çalışılan & 3 Y $_{1} \mathrm{ld}_{12}$ & 163 & 176,87 & 10,375 & 2 & ,006 & $1<3$ \\
\hline İşletmenin & 4 Yildiz & 109 & 213,51 & & & & $2<3$ \\
\hline Yildız Sayısı & 5 Yildiz & 125 & 215,21 & & & & \\
\hline
\end{tabular}

\section{Katılımcıların Özellikleri ile YíD'na İlişkin Farklılık Testleri}

İkili gruplar arası farkın belirlenebilmesi için analizde Mann Whitney U testi kullanılmıştır. Tablo 4'e göre katılımcıların cinsiyetlerine göre YİD puanları arasındaki farklılık istatistiksel olarak anlamlı değildir $(p, 776>0.05)$. Katılımcıların YİD medeni duruma göre anlamlı bir farklılık 
göstermektedir (p.001<0.05). Evli katılımciların YİD puan ortalamaları $(\overline{\mathrm{X}}$ $=215,32)$ bekar katılımciların YID puan ortalamalarından $((\bar{X}=178,71)$ daha yüksektir.

Tablo 4. Katılımcıların YiD Puanlarının Cinsiyet ve Medeni Duruma Göre Farklılığını Gösteren Mann Whitney U Testi Sonuçları

\begin{tabular}{llllllll}
\hline Değişkenler & Gruplar & $\mathbf{N}$ & $\begin{array}{l}\text { Sıra } \\
\text { Ortalaması }\end{array}$ & $\begin{array}{l}\text { Sıra } \\
\text { Toplamı }\end{array}$ & $\begin{array}{l}\text { Man- } \\
\text { Whitney } \\
\text { U }\end{array}$ & Z & p \\
\hline \multirow{2}{*}{ Cinsiyet } & Kadın & 168 & 197,10 & 33112,50 & 18916,500 &,- 284 &, 776 \\
\multirow{2}{*}{ Medeni } & Erkek & 229 & 200,40 & 45890,50 & & & \\
\cline { 2 - 8 } Durum & Evli & 220 & 215,32 & 47371,00 & 15879,000 & $-3,178$ &, 001 \\
\hline
\end{tabular}

${ }^{*} \mathrm{p}<0.05$

İkiden daha fazla grup arasındaki farkın belirlenebilmesi için analizde Kruskall Wallis Testi testi kullanılmıştır. Ayrıca farklılıkların kaynağını belirleyebilmek her bir grup, ikili gruplar halinde alınarak, MannWhitney U testine tabi tutulmuşlardır.

Tablo 5'e göre katılımcıların eğitim düzeyine göre YİD puanları arasindaki farklılık istatistiksel olarak anlamlı değildir $(\mathrm{p}, 358>0.05)$.

Katılımcıların yaş düzeyine göre YİD puan ortalamaları istatiksel olarak anlamlıdır $(\mathrm{p}, 000<0.05)$. Yapılan Mann-Whitney $\mathrm{U}$ testi sonucuna göre; yaş grubu 18-22 yaş arasındaki katılımcılar $(\overline{\mathrm{X}}=168,02), 33-37$ yaş $(\overline{\mathrm{X}}$ $=237,78), 38-42$ yaş $(\bar{X}=208,32)$ ve $43-47$ yaş $(\bar{X}=224,70)$ gruplarına göre; yaş grubu 23-27 yaş arasındaki katılımcilar $(\bar{X}=162,70)$, 33-37 yaş $(\bar{X}$ $=237,78), 43-47$ yaş $(\bar{X}=224,70)$ ve 48 yaş ve üzeri $(\bar{X}=252,59)$ gruplarına göre; yaş grubu 28-32 yaş arasındaki katılımcılar $(\overline{\mathrm{X}}=166,10)$, 33-37 yaş $(\overline{\mathrm{X}}$ $=237,78), 43-47$ yaş $(\bar{X}=224,70)$ ve 48 yaş ve üzeri $(\bar{X}=252,59)$ gruplarına göre daha düşük YİD puan ortalamasına sahiptirler. Genel bir ifade ile yaş arttıkça YİD puan ortalamalarının da arttığı ifade edilebilir.

Katılımcıların işletmedeki pozisyonuna göre YİD puanları istatiksel olarak anlamlıdır (p,000<0.05). Yapılan Mann-Whitney U testi sonucuna göre; işletme müdürlerinin YİD puan ortalamaları $(\bar{X}=311,81)$ çalışanların YİD puan ortalamalarından $(\bar{X}=192,50)$ daha yüksektir. Ayrıca departman müdürlerinin YİD puan ortalamaları $(\bar{X}=319,86)$ şef $(\bar{X}=195,22)$ ve çalışan pozisyonundaki katılımcıların YID puan ortalamalarından $(\overline{\mathrm{X}}$ 
$=192,50)$ daha yüksektir. Elde edilen verilere göre işletmede en az YİD çalışanlar tarafından gerçekleştirilmektedir.

Tablo 5. Katılımcıların YiD Puanlarının Yaş, Eğitim Düzeyi, İşletmedeki Pozisyon, Sektördeki Çalışma Süresi, İşletmedeki Çalışma Süresi, Çalışılan İşletmenin Yıldız Sayısına Göre Farklılı̆̆ını Gösteren Kruskall Wallis Testi Sonuçları

\begin{tabular}{|c|c|c|c|c|c|c|c|}
\hline Değişkenler & Gruplar & $\mathbf{N}$ & $\begin{array}{l}\text { Sira Orta- } \\
\text { lamasi }\end{array}$ & $\begin{array}{l}\text { Chi- } \\
\text { Square }\end{array}$ & df & $\mathrm{p}$ & Fark \\
\hline \multirow{7}{*}{ Yaş } & $18-22$ & 24 & 168,02 & 30,814 & 6 & ,000 & $1<4$ \\
\hline & $23-27$ & 78 & 162,70 & & & & $3<7$ \\
\hline & $28-32$ & 67 & 166,10 & & & & $1<6$ \\
\hline & $33-37$ & 55 & 237,78 & & & & $2<4$ \\
\hline & $38-42$ & 81 & 208,32 & & & & $2<6$ \\
\hline & $43-47$ & 81 & 224,70 & & & & $2<7$ \\
\hline & 48 ve üzeri & 11 & 252,59 & & & & $3<4$ \\
\hline \multirow{5}{*}{ Eğitim Düzeyi } & Orta & & 203.58 & 32207 & 3 & 358 & \\
\hline & Öğrenim & 39 & 203,00 & $3,2 \angle 21$ & 3 & 落, & \\
\hline & Lise & 147 & 210,49 & & & & \\
\hline & Önlisans & 128 & 194,17 & & & & \\
\hline & Lisans & 83 & 183,95 & & & & \\
\hline \multirow{6}{*}{$\begin{array}{l}\text { İşletmedeki Po- } \\
\text { zisyon }\end{array}$} & İşletme & \multirow{2}{*}{8} & \multirow[t]{2}{*}{311,81} & \multirow[t]{6}{*}{21,210} & \multirow[t]{6}{*}{3} & \multirow[t]{6}{*}{, 000 } & $1<4$ \\
\hline & Müdürü & & & & & & $2<3$ \\
\hline & Departman & 11 & 319,86 & & & & $2<4$ \\
\hline & Müdürü & 11 & & & & & \\
\hline & Şef & 83 & 195,22 & & & & \\
\hline & Çalışan & 295 & 192,50 & & & & \\
\hline \multirow{4}{*}{$\begin{array}{l}\text { Sektördeki Çalış- } \\
\text { ma Süresi }\end{array}$} & 5 yıldan az & 113 & 163,08 & \multirow[t]{4}{*}{23,278} & \multirow[t]{4}{*}{3} & \multirow[t]{4}{*}{0,000} & $1<3$ \\
\hline & 5-10 y1l & 126 & 193,06 & & & & $1<4$ \\
\hline & $11-15$ y1l & 114 & 225,43 & & & & \\
\hline & $\begin{array}{l}16 \text { yil } \\
\text { ve üzeri }\end{array}$ & 44 & 239,77 & & & & \\
\hline \multirow{4}{*}{$\begin{array}{l}\text { İşletmedeki Ça- } \\
\text { lışma Süresi }\end{array}$} & 1 yıldan az & 119 & 149,87 & \multirow[t]{4}{*}{42,134} & \multirow[t]{4}{*}{3} & \multirow[t]{4}{*}{, 000 } & $1<2$ \\
\hline & $1-5$ yıl & 196 & 207,19 & & & & $1<3$ \\
\hline & 6-10 yıl & 76 & 245,47 & & & & $1<4$ \\
\hline & $\begin{array}{l}11 \text { yıl } \\
\text { ve üzeri }\end{array}$ & 6 & 317,33 & & & & \\
\hline \multirow{3}{*}{$\begin{array}{l}\text { Çalışılan İşletme- } \\
\text { nin Yıldız Sayısı }\end{array}$} & 3 Yild1z & 163 & 173,73 & \multirow[t]{3}{*}{17,466} & \multirow[t]{3}{*}{2} & \multirow[t]{3}{*}{,000 } & $1<3$ \\
\hline & 4 Yildiz & 109 & 200,83 & & & & $2<3$ \\
\hline & 5 Yıldız & 125 & 230,39 & & & & \\
\hline
\end{tabular}

${ }^{*} p<0.05$ 
Katılımcıların sektördeki çalışma süresine göre YİD puanları istatiksel olarak anlamlıdır ( $\mathrm{p}, 000<0.05)$. Yapılan Mann-Whitney U testi sonucuna göre; sektördeki çalışma süresi 5 yıldan az olan katılımcıların YİD puan ortalamaları $(\bar{X}=163,08)$ sektördeki çalışma süresi $11-15$ yıl $(\bar{X}=225,43)$ ve 16 yıl ve üzeri olan katılımcıların YİD puan ortalamalarından $(\bar{X}$ $=239,177)$ daha düşüktür. Elde edilen verilere göre işletmede en az YİD sektördeki çalışma süresi 5 yıldan daha az olan katılımcılar tarafından gerçekleştirilmektedir.

Katılımcıların işletmedeki çalışma süresine göre YİD puanları istatiksel olarak anlamlıdır ( $\mathrm{p}, 000<0.05)$. Yapılan Mann-Whitney U testi sonucuna göre; işletmedeki çalışma süresi 1 yıldan az olan katılımcıların YİD puan ortalamaları $(\bar{X}=149,87)$ işletmedeki çalışma süresi $1-5$ yıl $(\bar{X}$ $=207,19), 6-10$ y1l $(\bar{x}=245,47)$ ve 11 yıl ve üzeri olan katılımciların YİD puan ortalamalarından $(\bar{X}=317,33)$ daha düşüktür. Elde edilen verilere göre işletmede en az YİD işletmedeki çalışma süresi 1 yıldan az olan katılımclar tarafından gerçekleştirilmektedir.

Katılımcıların çalışılan işletmenin yıldız sayısına göre YID puanları istatiksel olarak anlamlıdır $(\mathrm{p}, 000<0.05)$. Yapılan Mann-Whitney U testi sonucuna göre; 3 yıldızlı otel işletmelerinde çalışan katılımcıların YİD puanları $(\bar{X}=230,39), 4$ yıldızlı $(\bar{X}=200,83)$ ve 5 yıldızlı otel işletmelerinde çalışan katılımcıların YID puan ortalamalarından $(\bar{X}=173,73)$ daha düşüktür. Elde edilen verilere göre işletmede en az YİD 3 yıldızlı otel işletmelerinde çalışan katılımcılar tarafından hissedilmektedir.

\section{Tartışma ve Sonuç}

Eder ve Eisenberger (2008)'in belirttiği üzere, örgütsel destek konusunda yüksek algıya sahip çalışanlar, örgütleri hakkında daha olumlu duygulara sahip olmak, örgütlerine daha fazla katkıda bulunmak ve performans algısını artırmak için daha fazla çalışmaktadırlar.

Araştırmadan elde edilen sonuçlarda konaklama işletmesi çalışanlarının AÖD ve YID arasında istatistiksel açıdan pozitif yönde, orta düzeyde ve anlamlı bir ilişki olduğu sonucuna ulaşılmıştır. Çıkan sonuç Çapraz vd. (2014), Yıldız, vd. (2017), Qi, vd. (2019) ve Özer (2014)'in çalışmalarını desteklemektedir. 
Ayrıca hem AÖD hem de YİD ile cinsiyet ve eğitim düzeyi değişkeni arasında istatistiki olarak anlamlı bir farklılık bulunamamıştır. Buna karşın AÖD ile YİD ile medeni durum, yaş, işletmedeki pozisyon, sektördeki çalışma süresi, işletmedeki çalışma süresi ve çalışılan işletmenin yıldız sayısı değişkenleri arasında istatiksel olarak anlamlı farklılıklar bulunmuştur.

Araştırma sonuçları genel olarak ifade edildiğinde; evli olan katılımcıların AÖD algısı bekar katılımcılara göre daha yüksektir. AÖD algıs1nın; yaş, işletmedeki pozisyon, sektördeki çalışma süresi ve işletmedeki çalışma süresi arttıkça arttığı belirlenmiştir. Ayrıca işletmenin yıldız sayısı arttıkça AÖD algısının artmakta görülmektedir.

AÖD ve değişkenler arasındaki sonuçlar değerlendirildiğinde; Blau'nun "Sosyal Değişim Teorisi" ve Levinson'ın "Kişileştirme Teorisi" uyarınca ortaya çıkan karşılıklılık normu temel alındığında; yaş, işletmedeki pozisyon, sektördeki çalışma süresi ve işletmedeki çalışma süresi arttıkça AÖD puanlarının artması beklentisinin karşılandığı görülmektedir. Çalışanlar tarafından, örgüt temsilcilerinin davranışlarının, örgüt politikalarının, normların zaman içerisinde karşılıklı olarak daha iyi anlaşılacağ 1 ve örgüt içerisinde olumlu bir iklim oluşturacağı düşünülmektedir. Benzer biçimde bu süreçte işletme çalışanlarının onay, saygınlık ve sosyal kimlik ihtiyaçlarının karşılanması ve işletmeye sundukları katkılarının işletme tarafından farkında olunduğunun algılanması buna karşılık olarak sergiledikleri extra rol davranışlarının farklı biçimlerde (maaş artışı, yükselme, takdir edilme vb.) ödüllendirilmesi AÖD algısının yüksek çıkması sonucunu doğuracaktır. İşletmenin yıldız sayısı arttıkça AÖD algısının artması kurumsallaşma ile birlikte işletmeye olan güvenin ve insan kaynaklarının etkinliğinin artması ile ilgili olduğu düşünülmektedir.

AÖD puanlarına benzer bir biçimde evli olan katılımcıların YİD bekar katılımcılara göre daha yüksektir. Araştırma sonuçları genel olarak ifade edildiğinde; YİD genel olarak yaş arttıkça artmaktadır. İşletme müdürü ve departman müdürlerinin YİD puanları da şef ve çalışanlara göre daha yüksektir. Sektördeki çalışma süresi ve işletmedeki çalışma süresi arttıkça da YİD artmaktadır. Ayrıca işletmenin yıldız sayısı arttıkça YİD’nın artmakta olduğu görülmektedir. 
YİD sonuçlarının AÖD algısı sonuçları ile paralellik göstermesi araştırmada beklenen bir sonuçtur. Blau'nun “Sosyal Değişim Teorisi"'ne göre konaklama işletmesi çalışanlarının işletme ile ilgili algısı olumlu olduğunda davranışlarının da olumlu olacağı ve örgüt adına yapılan çalışmalarını ve verimliliğini arttıracağı beklenmektedir. Dolayısı ile AÖD algısının yaş, işletmedeki pozisyon, sektördeki çalışma süresi ve işletmedeki çalışma süresi ve yıldız sayısı arttıkça artması konaklama işletmelerinde YİD'nı da arttırmaktadır. Ayrıca çalışanın deneyim ve tecrübesinin artması ile birlikte YİD göstermesinin ilişkili olduğu ifade edilebilir. İşletmenin yıldız sayısı arttıkça YİD’nın artması kurumsallaşmanın getirdiği stratejik düşünme ve çalışana fikrini ifade etme, fikri destekleme, gerekli kaynakları sağlama, risk alabilme gibi avantajları sağlamasının sonucu olarak düşünülmektedir. Ulusal ve uluslararası pazarlarda inovatif strateji eksikliği beraberinde riski de getirmektedir. Kurumsallaşmış işletmeler bu durumun daha farkında olan işletmelerdir.

Günümüz iş dünyasında yenilik yapma bütün çalışanların temel amacı olmalıdır. Bunun içinde işletmenin vizyonu belirlenmeli, inovasyon odaklı iş stratejileri oluşturulmalıdır. Çalışanların örgüte yaptıkları katkılar teşvik edilmeli ve örgüte katkı sağlamaları için motive edilmelidirler. Bu bakış açısıyla yenilikçi fikirler geliştirebilmeleri açısından uygun yenilik atmosferi oluşturulmalı, çalışanların fikirleri dinlenilmeli, gerekli kaynaklar sağlanmalı, elde edilen sonuçlar olumlu olduğunda çalışanların ödül vb. beklentileri karşılanmalıdır. Riskler birlikte karşılanmalı olası başarısızlıklar da çalışanlar sorumlu tutularak tek başına bırakılmamalıdır. Ayrıca yöneticilerin ve çalışanların arasındaki etkileşimde bilgi paylaşımının rolü dikkate alınmalıdır.

Çalışmanın evreni Türkiye'de Çanakkale il merkezinde faaliyet gösteren 3, 4 ve 5 yıldızlı konaklama işletmesi çalışanları ile sınırlıdır. Daha farklı bir evrende çalışmanın yenilenmesi aynı zamanda YİD'nın arttırılmasında etkisi bulunabilecek farklı değişkenlerin de ilave edilerek çalışmanın devam ettirilmesinin literatüre katkı sağlayacağı düşünülmektedir. 


\title{
EXTENDED ABSTRACT
}

\section{The Relationship Between The Perceived Organizational Support and Innovative Business Behavior in theHospitality Management}

\author{
Sibel Sü Eröz - Seher Şıttak \\ KırklareliUniversity
}

It can be stated that the intensity of the global competition in the tourism sector is increasing and hospitality companies are affected the most. Rivalry in hospitality management is ensured by the qualifications of the employees, and the presence of entrepreneurial, creative and openminded employees increases the quality of service and customer satisfaction within the management. The importance and support given to the employees by the managements become crucial at this point, but the perception of employees about this support is also very important. We can say that both innovation and the adoption and application of innovation are related to the innovative work behavior of employees. Eisenberger et al. (1990) state that innovation and spontaneous problem solving can be associated with perceived support. Similarly, Y1ld1z, Uzun and Coşkun (2017) predict that psychological empowerment and support of employees will increase their innovative behaviors in the workplace based on social change theory and organizational support theory. Therefore, in this study, that employees will focus more on innovation when they perceive positive organizational support is considered, and the relationship between Perceived Organizational Support (POS) and Innovative Business Behavior (IBB) is observed.

In the study the answers to the following questions are sought;

1. Is there a relationship between the POS and IBB perception of the hospitality management employees?

2. Do the POS perceptions of the hospitality management employees differ according to the categorical questions (gender, marital status, age, education level, position in the management, working time in the industry, working time in the management, number of stars of the management)? 
3. Do the IBB perceptions of the hospitality management employees differ according to the categorical questions (gender, marital status, age, education level, position in the management, working time in the sector, working time in the management, number of stars of the management)?

In order to collect the essential data, "Personal Information Form", "Perceived Organizational Support Scale" developed by Eisenberger et al. (1997) and "Innovative Behavior Scale" developed by De Jong and Den Hartog (2010) were used.

Population of the research is the employees of the 3,4 and 5 star hospitality management at the city center of Çanakkale/Turkey. 397 employees were reached in the study. Data were analyzed with IBM SPSS Statistic 20.0 statistical software. As a result of the reliability analysis done with the data obtained; Cronbach's Alpha value was found to be 0.899 $(n=18)$ for all statements in the scale. As a result of the factor analysis, a single factor structure was obtained for both scales. In addition, it was observed that the data subjected to normality tests with KolmogorovSmirnov and Shapiro-Wilks did not show normal distribution.

According to the results obtained from the study, it was concluded that there was a statistically positive, medium level and significant correlation between the POS and IBB of the hospitality management employees $(0.000<0.05, r=, 490, N=397)$. The results supports the study of Çapraz et al. (2014), Yıldiz, et al. (2017), Qi, et al. (2019) ve Özer (2014). In addition, no statistically significant difference was found between the variables of gender and education level for both POS and IBB. On the other hand, statistically significant differences were found between variables of marital status, age, position in the management, working time in the sector, working time in the management and the number of stars of the management.

When the results between POS and variables were evaluated; based on the norm of reciprocity coming out of Blau's "Social Change Theory" and Levinson's "Personification Theory"; age, position in the management, working time in the sector and working time in the management increased, it is seen that the expectation of increasing the POS scores is met. It is thought that the behaviors of the representatives of the organization, the policies of the organization and the norms will be better understood by the employees in time and create a positive climate within 
the organization. Similarly, in this process, POS perception will be high, if management employees' approval, respectability and social identity needs are met, the company is aware of their contributions to the business and in return to the extra role behaviors they show, they are rewarded in different forms (salary increase, advance, appreciation, etc.) As the number of stars increases, the increase in the perception of POS is thought to be related to the increase in the confidence in the management and the efficiency of human resources with institutionalization.

The result of IBB is parallel to the perception of POS and this is expected in the survey. According to Blau's "Social Change Theory", when the perception about the management of hospitality employees is positive, their behaviors will be positive and they will increase their work and productivity on behalf of the organization. Therefore, while the perception of POS increases with the increase of age, position in the management, working time in the sector and working time in the management and the number of stars, it also increases the IBB in hospitality managements. In addition, it can be stated that increasing IBB is related with the employee's experience. The increase in IBB as the number of stars increases is considered as a result of taking the advantage of the strategic thinking, expressing the idea, supporting their ideas, providing the necessary resources and taking risks which are brought by institutionalization. The lack of innovative strategies in national and international markets poses a risk. Institutionalized managements are more aware of this situation.

Innovation in today's business world should be the primary goal of all employees. Therefore, the vision of the management should be determined and innovation-oriented business strategies should be established. Employees' contributions to the organization should be encouraged and they should be motivated to contribute to the organization. With this perspective, an appropriate atmosphere of innovation should be created in order to develop innovative ideas, the ideas of the employees should be listened, the necessary resources should be provided, and if the results are positive they should be rewarded through their expectations. Risks must be met together and possible failures should not be left on the employees alone by holding them blameworthy. In addition, the role of 
information sharing in the interaction between managers and employees is essential.

\section{Kaynakça / References}

Altunışık, R., Coşkun, R., Bayraktaroğlu S. ve Yıldırım, E. (2007). Sosyal bilimlerde araştırma yöntemleri SPSS uygulamalı. 5. baskı. Sakarya: Sakarya yayıncllik.

Aselage, J. ve Eisenberger R. (2003). Perceived organizational support and psychological contracts: A theoretical integration. Journal of Organizational Behavior, 24, 491-509.

Cropanzano, R. ve Mitchell M. S. (2005). Social Exchange theory: An interdisciplinary review. Journal of Management, 31(6), 874-900.

Crossan, M. M. ve Apaydin M. (2010). A multi-dimensional framework of organizational innovation: A systematic review of the literatüre. Journal of Management Studies 47(6), 1154-1191.

Çapraz, B., Ayyıldız Ünnü N. A., Kelgokmen İlic D., Kocamaz M., Çiçekli U. G., Aracıŏ̆lu B., Koçak A., Kesken J. ve Soyuer H. (2014). Çalışanlar perspektifinden inovatif iş davranışının belirleyicileri: İzmir ilindeki öncelikli sektörlere ilişkin bir araştırma. Girişimcilik ve İnovasyon Yönetimi Dergisi, 3(1), 49-72.

Çimen, İ. ve Yücel C. (2017). Yenilikçi davranış ölçeği (YDÖ): Türk kültürüne uyarlama çalışması. Cumhuriyet Uluslararası Ĕ̆itim Dergisi, 6(3), 365-381.

Çokluk, Ö., Şekercioğlu G. ve Büyüköztürk Ş. (2016). Sosyal bilimler için çok değişkenli istatistik SPSS ve LISREL uygulamaları. Ankara:PegemAkademi,.

De Jong, J. P. J. ve Den Hartog D. N. (2008). Innovative work behavior: measurement and validation. SCALES, Zoetermeer, 1-27.

Dolanay, S. S. (2009). Schumpeter sisteminde yenilikler, ekonomik gelişme ve devresel hareketler. Ulusararası İktisadi ve İdari İncelemeler Dergisi, 1(2), 171-188.

Eder, P. ve Eisenberger R. (2008). Perceived organizational support: Reducing the negative influence of coworker withdrawal behavior. Journal of Management, 34(1), 55-68. 
Eisenberger, R, Fasolo P. ve Davis-LaMastro V. (1990). Perceived organizational support and employee diligence, commitment, and innovation. Journal of Applied Psychology, 75(1), 51-59.

Eisenberger, R., Cummings J., Armeli S. ve Lynch P. (1997). Perceived organizational support, discretionary treatment, and job satisfaction. Journal of Applied Psychology, 82(5), 812-820.

Eisenberger, R., Huntington, R., Hutchison S. ve Sowa, D. (1986). Perceived organizational support. Journal of Applied Psychology, 7, 500-507.

Güçlü Nergiz, H. (2016). Otel işletmelerinde çalışanların algıladıkları destek boyutları üzerine bir model önerisi. ÇOMÜ Uluslararası Sosyal Bilimler Dergisi, 1(2),1-14.

Hellman, C. M., Fuqua D. R. ve Worley J. (2006). A reliability generalization study on the survey of perceived organizational support the effects of meanage and number of items on score reliability. Educational and Psychological Measurement, 66(4), 631-642.

Janssen, O. (2000). Job demands, perceptions of effort-reward fairness and innovative work behaviour. Journal of Occupational and Organizational Psychology; Leicester, 73, 287-302.

Karasar, N. (2009). Bilimsel Araştırma Yöntemi. Ankara: Nobel Yayın-Dağıtım.

Kurtessis, J. N., Eisenberger R., Ford M. T., Buffardi L. C., Stewart K. A. ve Adis C. S. (2015). Perceived organizational support: A meta-analytic evaluation of organizational support theory. Journal of Management, 20(10), 1-31.

$\mathrm{Li}, \mathrm{X}$. ve Zheng, Y. (2014). The influential factors of employees' innovative behavior and the management advices. Journal of Service Science and Management, 7(6), 446-450.

Özer, Y. (2014). Algllanan örgütsel destek ve kişilik özelliklerinin takım inovasyonu üzerine etkisi: Türk Telekomünikasyon A.Ş. üzerine bir araştırma. Basılmamış Yüksek Lisans Tezi. Marmara Üniversitesi, SBE, İşletme ABD, Uluslararası İşletmecilik Bilim Dalı, İstanbul.

Qi, L., Liu B., Wei X. ve Hu Y. (2019). Impact of inclusive leadership on employee innovative behavior: Perceived organizational support as a mediator, PLoSOne 14 (2), e0212091. https://doi.org/10.1371/journal.pone.0212091.

Rhoades, L. ve Eisenberger, R. (2002). Perceived organizational support: A review of the literatüre. Journal of Applied Psychology, 87(4), 698-714. 
Stamper, C. L. ve Mark C. J. (2003). The impact of perceived organizational support on the relationship between boundary spanner role stres and work outcomes. Journal of Management, 29(4), 569-588.

Yıldız, B., Uzun S. ve Coşkun S. S. (2017). Drivers of innovative behaviors: The moderator roles of perceived organizational support and psychological empowerment. International Journal of Organizational Leadership 6,341-360.

Yuan, F. ve Woodman, R. W. (2010). Innovative behavior in the workplace: The role of performance and image outcome expectations.Academy of Management Journal, 53(2), 323-342.

\section{KaynakçaBilgisi / Citation Information}

Sü-Eröz, S. ve Şıttak, S. (2019). Konaklama işletmelerinde algılanan örgütsel destek ve yenilikçi iş davranışı arasındaki ilişki. OPUSUluslararası Toplum Araştırmaları Dergisi, 13(19), 1574-1599. DOI: 10.26466/opus.578547 